\title{
Erratum to: Spinal leptomeningeal metastases from prostate cancer
}

\author{
R. Deinsberger • R. Regatschnig • B. Kaiser • \\ H. C. Bankl
}

Received: 1 December 2009 / Published online: 23 February 2010

(C) Springer-Verlag 2010

\section{Erratum to: Acta Neurochir}

DOI 10.1007/s00701-005-0687-z

It has been brought to our attention that this article represents a duplicate publication of an article originally published in the "Journal of Neuro-Oncology" published by Springer (R. Deinsberger, R. Regatschnig, B. Kaiser, H.C. Bankl in Journal of Neuro-Oncology 76:293-297, 2006).

After carefully checking the circumstances with the responsible corresponding author and Springer, this appears to be an unfortunate result stemming from a misunderstanding of the author in the course of submitting this paper to Acta Neurochirurgica.

In order to appropriately correct this situation and to comply with Springer's policy of publishing integrity, which also follows the recommendations of COPE, we have therefore agreed with the author and with our colleagues at Springer responsible for the Journal of Neuro-Oncology to the retraction of this article.

Acta Neurochirurgica sincerely regrets the circumstances that have led to this situation and any inconvenience that might have arose.

The online version of the original article can be found under doi:10.1007/ s00701-005-0687-z.

R. Deinsberger $(\triangle) \cdot$ R. Regatschnig $\cdot$ B. Kaiser $\cdot$ H. C. Bankl

Department of Neurosurgery, Landesklinikum St. Poelten,

St. Poelten, Austria

e-mail: Robert.Deinsberger@stpoelten.lknoe.at 